\title{
Economias-Políticas Marginais: Produtividade Policial, Vizinhanças Radicais e a (Re)Produção Cotidiana das Desigualdades em uma Favela de Niterói-RJ
}

\author{
Marginal Political-Economies: Police Productivity, Radical \\ Neighborhood Situations and the Everyday (Re)Production of \\ Inequalities in a Niterói-RJ Favela
}

\section{Elizabete Ribeiro Albernaz}

University of the Witwatersrand, Johannesburg, África do Sul

\section{RESUMO}

Qual é a política da segurança, para além da política de segurança pública? A polícia justifica sua existência profissional pela atribuição de fiscalizar e garantir a adesão dos indivíduos a um determinado regramento, seja ele legal ou consuetudinário. A lei, entretanto, não é capaz de antever todas as condutas concretas dos sujeitos, e a polícia, por sua vez, também não é sua mera replicadora. Seu espectro de intervenção (o que a polícia de fato faz) supera de longe o argumento que justifica a legalidade de suas ações e seus objetivos manifestos. No caso do Morro do Palácio, uma favela de Niterói, busquei apresentar os efeitos de repercussão da atuação policial para além de suas consequências imediatas sobre o cotidiano da favela, explorando sua dimensão política e seus potenciais rendimentos econômicos, entre o legal e ilegal. Nesse sentido, busquei destacar o papel da segurança no funcionamento de dispositivos de reprodução da estrutura das desigualdades e seus rituais de desigualação em sua operação insidiosa sob o manto da democracia participativa brasileira. Essas forças de conservação na mudança, trabalhando fortemente ancoradas no cotidiano palaciano, participavam da (re)produção do status quo da desigualdade social e da exclusão na cidade de Niterói. Em última análise, como mais tarde se tornou claro, a interação dessas forças resultava em uma elaborada técnica de governo, uma economia que tinha seu lado visível, beneficiando oligarquias políticas e econômicas, mas também jogava uma mão oculta nas sombras da ilegalidade, criando um ambiente lucrativo para todos os tipos de oportunistas da insegurança.

Palavras-chave: Polícia, Favela, Desigualdade, Cotidiano, Niterói. 


\section{ABSTRACT}

What is the politics of safety beyond the public safety policy? The police justify their professional existence by assigning to supervise and guarantee the adherence of individuals to a specific rule, be it legal or customary. The law, however, is not able to foresee all the concrete conduct of the subjects, and the police is also not its mere replicator. Its spectrum of intervention (which the police actually does) far exceeds the argument that justifies the legality of its actions and its manifest objectives. In the case of Morro do Palácio, a slum in Niterói, I tried to present the repercussion effects of police action beyond its immediate consequences on the daily life of the favela, exploring its political dimension and its economic potential, legal and illegal. In that sense, I sought to highlight the role of security in the functioning of dispositifs reproducing the structure of inequalities and their rituals, in their insidious operation under the cover of Brazilian participatory democracy. These forces of conservation in change, working strongly anchored in Palácio's everyday life, participated in the (re) production of the status quo of social inequality and exclusion in the city of Niterói. Ultimately, as it later became clear, the interaction of these forces resulted in an elaborate government technique, an economy that had its visible side, benefiting political and economic oligarchies, but also played a hidden hand in the shadows of illegality, creating a profitable environment for all types of insecurity opportunists.

Keywords: Police, Favela, Inequality, Everyday, Niterói.

More than ever before men now live in the shadow of the state. Ralph Miliband (1969, p. 1)

\section{INTRODUÇÃO}

O que é a "favela"? Favela" é uma categoria de difícil definição, primeiro em razão de sua diversidade. Várias configurações espaciais e humanas caracterizam locais de habitação popular chamados de favelas. Seus limites territoriais também costumam ser altamente debatíveis e imprecisos, bem como os critérios socioeconômicos que caracterizam as áreas classificadas como favelas. Confrontada por essa dificuldade, em minha pesquisa de doutorado (ALBERNAZ, 2018), escolhi tratar a favela como uma relação social (ou um feixe delas) ${ }^{2}$, uma posição

1 No presente artigo, o itálico será utilizado no caso da repetição de um conceito de um/a autor/a que já tenha sido citado no texto e para se referir a categorias utilizadas em sua acepção nativa, sentido este incorporado ao texto pela autora. As aspas serão utilizadas em citações e expressões extraídas de entrevistas e relatos registrados em cadernos de campo, bem como conceitos, no caso de sua primeira citação, seguidos da referência no texto.

2 Nesse sentido, inspiramo-nos nas análises de Georg Simmel sobre a constituição social da "pobreza" na relação 
relativa em um campo de forças que conformam a experiência citadina da desigualdade social. Minha tese fala de uma favela em especial, o Morro do Palácio, uma comunidade de médio porte de Niterói, município da Região Metropolitana do Rio de Janeiro. Situado na região das Praias de Baía, entre prédios luxuosos e o casario antigo de bairros tradicionais da classe média e média alta da cidade (Ingá, São Domingos e Boa Viagem), o Palácio é uma favela "altamente politizada", como gostam de dizer suas lideranças. Em razão de sua "situação de vizinhança radical" (ALBERNAZ, 2018), as coisas que acontecem no Palácio repercutem fortemente na opinião pública niteroiense.

Como em tantas outras favelas, o Palácio tem sua existência social associada a um imaginário de ausência e precariedade, de informalidade e ilegalidade. Na sua relação com o seu entorno abastado, esse imaginário articula dispositivos discursivos responsáveis pela produção do Morro do Palácio como um lugar da pobreza em Niterói. O funcionamento desse dispositivo afeta o cotidiano de palacianos e palacianas de diversas maneiras; uma delas é a violência das incursões policiais, espetáculo repressivo de amplas repercussões políticas na cidade. Minha pesquisa dedicou-se a etnografar algumas das mecânicas cotidianas por meio dos quais o Estado, como uma sombra, reproduz-se a partir de sua suposta "ausência" no Morro do Palácio. Para tanto, dediquei-me a observar universos relacionais e processos multiescalares de repercussão da violência urbana em Niterói, um discurso fortemente marcado por uma oposição imaginada entre a cidade "legal" e "ilegal". No Morro do Palácio, observei que, no lusco-fusco de um "Estado ausente", um estado policial encontrava espaço para monetizar a sua violência em estreita cooperação com as forças econômicas que pretensamente buscava combater.

No presente artigo, abordarei essa questão à luz de uma dialética de produção periférica do Estado e de reprodução estatal das "margens", estas últimas entendidas enquanto lugares, posições e representações construídas em relação a ideais projetados de legalidade e centralidade associados ao campo estatal e suas figuras de poder (DAS; POOLE, 2004). No caso do Morro do Palácio, chamarei a atenção do/a leitor/a para a ideia de "alternância de ciclos de violência" e o papel da polícia nessa dinâmica, contribuindo para a produção da favela como um "lugar violento" na paisagem urbana de Niterói. Argumento que a constituição da pobreza

com a formação do "Estado moderno" na Europa. Para o autor, o "pobre", em sua constituição identitária, de pertencimento a uma camada específica da sociedade, é alguém que é publicamente reconhecido como uma pessoa que carece da "assistência" por parte de uma coletividade; a "pobreza", nesse sentido, surge a partir de feixes de relações de cooperação e conflito, de interdependência simbólica e material entre indivíduos e grupos de indivíduos desiguais entre si. Nas palavras do autor, “(...) não é a pobreza em si nem a entidade dos pobres em si mesmos, mas as formas institucionais que eles assumem numa dada sociedade num momento específico de sua história. Essa sociologia da pobreza, em realidade, é uma sociologia dos laços sociais" (SIMMEL, 1998). 
urbana niteroiense e seus locais de morada, como o Morro do Palácio, deve ser buscada nas relações estruturais de suas favelas com a economia e a política local, das dinâmicas de conflito e cooperação, conservação e mudança que imprimiram (e ainda imprimem) as hierarquias sociais no espaço daquela cidade.

Em 2016, quando iniciei minha atividade de campo mais intensiva no Morro do Palácio, as pessoas comentavam que a "favela era só lazer". Essa referência de tranquilidade era construída a luz de um tempo pretérito, mas não tão distante, em que a população palaciana tinha se visto pela última vez dragada pela violência das lutas faccionais e da repressão policial. Essa época era referida, na linguagem cotidiana, como "a época da guerra", quando a favela tinha "mudado de facção". O relativo período de tranquilidade, segundo a percepção dos moradores locais, teria se iniciado a partir da vinda da base da Polícia Militar (PM). Precariamente instalada na parte mais alta da favela desde 2013, a base era vista pelos moradores do Morro do Palácio como um marco para o fim das tentativas de invasão da facção vencida, um fator de relativa estabilidade para o cotidiano da favela.

No início de 2017, entretanto, uma nova ressaca se anunciava em costas palacianas. Depois de um ano de trabalho de campo sem ouvir sequer um disparo de arma de fogo, nas vésperas da minha viagem para a África do Sul, onde desenvolvi meu Doutorado Sanduíche ${ }^{3}$, quatro pessoas tinham sido mortas no período de pouco mais de um mês; todas alegadamente pelas mãos da PM. Os rumores de invasão também tinham voltado a circular pela favela, deixando apreensivos seus moradores. O que havia mudado naquela configuração de forças? Por que a morte violenta era novamente uma sombra sobre as cabeças dos palacianos e palacianas?

Nas linhas que seguem, dedicar-me-ei a descrever eventos relacionados a atuação da Polícia Militar do Estado do Rio de Janeiro (PMERJ) no Palácio, chamando atenção para os impactos dessas ações sobre o cotidiano de seus moradores, mas também seus efeitos políticos mais amplos, perseguidos a partir da audiência de histórias pessoais, da circulação de rumores, do recurso a matérias jornalísticas, sites de internet. Farei menção também a minha experiência com o Conselho Comunitário de Segurança de Niterói (CCS-12), onde, a partir do início do ano de 2017, passei a acompanhar as reverberações da série de mortes ocorridas no Palácio naquele período. Falarei da relação das organizações policiais com a sociedade civil nesse espaço de "participação social", chamando atenção para uma discussão sobre "produtividade policial"

3 O presente trabalho beneficiou-se de financiamento concedido no âmbito do programa Doutorado Sanduíche no Exterior (CAPES/PDSE), integrando-se aos esforços despendidos pelo governo brasileiro, por intermédio da Coordenação de Aperfeiçoamento de Pessoal de Nível Superior, Ministério da Educação (CAPES/MEC), com vistas ao incremento do intercâmbio técnico-científico e consequente internacionalização de docentes e pesquisadores brasileiros. 
(ALBERNAZ, 2015a, 2015b).

\section{O BECO EM QUE SEU PAI MORREU}

A partir da morte de Sílvio, as coisas tinham voltado a ficar complicadas no Palácio. Tinha passado a ouvir tiros com mais frequência; o movimento parecia estar recebendo reforços, trazendo armas cada vez mais pesadas. Encontrava mais pessoas da boca de fumo patrulhando as vielas da favela. A conduta da polícia também tinha mudado; ela circulava então mais pelos becos, adotando uma postura mais agressiva em relação ao movimento, produzindo mais prisões, apreensões e letalidade. O Palácio tinha estado tranquilo por muito tempo. Naquela época, não sabia ao certo o que estava acontecendo e a favela estava rumorosa. A mudança de postura dos atores da "sociabilidade violenta" (MACHADO DA SILVA, 2004) 4 era notória. À boca muito miúda, comentava-se que os "pactos" vigentes tinham sido quebrados e que a cobrança pelo seu restabelecimento seria violenta. Naquela época eu visitava a favela diariamente.

Numa dessas visitas, durante uma partida de futebol, uma mensagem chega pelo celular. "Tem um cara morto na Barreira", me avisa Wellerson, grande amigo e um de meus principais interlocutores no Palácio à época; era a terceira morte de um "envolvido" (CECCHETTO; MUNIZ; MONTEIRO, 2018) em apenas um mês. Tínhamos ouvidos dois disparos. "Ih, é tiro!"; todos deixam o campo de futebol ordeiramente. A Barreira é considerada a entrada "social" da favela, acessível por meio de uma escadaria que leva o/a eventual visitante direto ao Maquinho, um equipamento da Prefeitura de Niterói ${ }^{5}$. Mais tiros foram ouvidos; agora na rua de baixo.

4 Empregamos aqui o conceito de "sociabilidade violenta" de Machado da Silva (2004) enquanto uma ordem social cujo princípio de organização é o recurso universal à força, que não dispõe de uma linguagem própria, recorrendo, para expressar-se como "forma de vida", a uma ressignificação da linguagem cotidiana. Seguimos a indicação do autor que afirma ser possível pensar a sociabilidade violenta como uma "empresa", no sentido weberiano, sem separar sua dimensão de empreendimento político e econômico. Em termos dos seus efeitos sobre o cotidiano, citamos diretamente o autor, "não se trata apenas do fechamento para os 'de fora' das populações mais diretamente afetadas pela sociabilidade violenta, mas da incomunicabilidade entre seus próprios membros produzida pelo medo e pela desconfiança. Esta talvez seja a consequência mais perversa da implantação da sociabilidade violenta como ordem instituída. As populações que ela submete continuam, de certa maneira, a viver sua vida 'normal', organizadas como subalternas que são à ordem estatal, mas sob a condição de serem impedidas de se apropriarem coletivamente da 'outra parte' desta mesma normalidade cindida" (MACHADO DA SILVA, 2004, p. 79).

5 Em sua face voltada para a Boa Viagem, os moradores do Palácio têm acesso a uma das vistas mais estonteantes de toda a cidade, vista esta que, de modo geral, é associada aos privilégios da classe média alta e alta de Niterói. No topo da escadaria que dá acesso a favela foi instalado um equipamento público da Prefeitura, a Plataforma Urbana Digital de Educação, inaugurada em 2014. O prédio é conhecido carinhosamente como "Maquinho" em alusão ao 
Depois de 40 minutos de um silêncio quase sepulcral, perguntei a Wellerson se já era seguro sair de casa. Ele já estava na Barreira, onde o rapaz tinha sido morto, e respondeu a minha pergunta afirmativamente. Sigo para lá. Chegando ao mirante do Maquinho, pude ver a silhueta do corpo de um rapaz caído de bruços na escada. As pernas estiradas ainda sobre os degraus, a cabeça espatifada no quadrado de cimento a sua frente como se tivesse perdido a consciência subitamente, em meio a tentativa desesperada de fuga. Vejo marcas de sangue no chão; as paredes tinham perfurações de disparos de arma de fogo. Vários policiais militares já faziam o isolamento do acesso a escada, impedindo as pessoas de se aproximarem do local onde estava o corpo.

Essa polícia que dava combate ao tráfico no Palácio, na época, vinha de fora e quando batia de frente com as pessoas erradas no beco podia participar de uma explosão de violência de consequências dramáticas e imprevisíveis. "Quando a polícia está no beco está à caça de alguém", diziam-me; essa polícia que buscava o confronto, o tiroteio, representava um risco real de violência para os moradores e moradoras. Os policiais militares da Companhia Destacada da PMERJ, precariamente instalados no topo do Palácio desde 2013, eram referidos localmente como a "polícia do container" e tinham uma postura bastante diferente da polícia que vinha de fora. Eles não entravam em choque com o movimento e até mantinham uma certa relação de proximidade - mesmo que tensa e suspeitosa - com a população local.

Na percepção dos moradores, desde a instalação da polícia do container, as coisas tinham ficado relativamente mais tranquilas no Palácio. Além da precariedade de suas instalações, as pessoas também comentavam que a atitude pacífica da polícia do container se devia ao "arrego" pago pela boca de fumo como parte dos pactos locais. "Tá tudo desenrolado", diziam-me. Pelo menos era essa a percepção das pessoas até antes da explosão de violência que teve na morte de Silvio um diacrítico importante, como veremos mais a frente. A presença da polícia do container, apoiada pelos recursos do batalhão, tinha reduzido sensivelmente os efeitos desagregadores da ameaça constante de invasão por parte de grupos de facções rivais.

\footnotetext{
Museu de Arte Contemporânea (MAC), e abriga diversas atividades e projetos socioeducativos destinados a toda a população do município. Dificilmente, entretanto, algum morador/a do entorno se aventura a subir o Palácio para frequentar o espaço, entretanto. Não só porque a população do entorno não atende ao perfil socioeconômico de beneficiários/as desse tipo de iniciativa, mas em razão do medo da violência e do estigma que acompanha a favela. Para muitas dessas pessoas, o Maquinho é apenas um anteparo material conveniente que as impede de observar o Palácio do ponto de vista do asfalto, situação esta questionada pelos moradores e moradoras do morro quando de sua inauguração. Segundo eles/elas, o prédio teria sido propositalmente construído de costas para a favela, obstruindo sua magnífica vista do litoral, salpicada de ilhotas e pequenas embarcações de pescadores.

6 Para uma análise comparada da categoria "arrego", ver PIRES, Lenin. Arreglar não é pedir arrego: uma etnografia de processos de administração institucional de conflitos no âmbito da venda ambulante em Buenos Aires e Rio de Janeiro. 2010.
} 
O movimento, resguardado por esse aporte de força, dizia-se, acabava sendo displicente com a segurança da boca e menos invasivos na regulação do cotidiano, muito diferente da regulação violenta implementada pela facção anterior, notabilizada pela agressividade nesse sentido.

Diante de mais aquele corpo, entretanto, as pessoas tinham certeza de que algo tinha mudado no equilíbrio de forças local. O Palácio não era mais "só lazer" e a mudança no padrão de atuação da polícia era um indicativo importante disso. "Estão matando todos os crias? da boca", as pessoas comentavam. Isso, na percepção de meus interlocutores, fortalecia as tentativas de retomada do grupo da facção rival que reclamava violentamente direitos sobre os mercados operados sob o lusco fusco legal da favela. Aquele rapaz, disseram, era "o último cria da boca"; todos os demais tinham perdido suas vidas nas mãos da polícia militar ou estavam presos, capturados pelas "intervenções cirúrgicas" da polícia civil ${ }^{8}$. Pela configuração da cena e a presença dos policiais do GAT (Grupamento de Ações Táticas) ${ }^{9}$ guardando o local da ocorrência, assumimos que uma das equipes da polícia militar que circulava pela favela naquela noite teria sido a autora. Pareceu-me que nada estava sendo passado para as pessoas no local; não tínhamos nenhuma informação "oficial" sobre o que tinha acontecido.

Mais tarde, naquela mesma noite, fotos do rapaz morto começaram a circular nas redes sociais, mostrando seu corpo, tombado desajeitado na escada. Na imagem, uma espécie de placa tinha sido adicionada digitalmente. Nela, era possível ler o nome da equipe de GAT responsável pela ocorrência. Não houve qualquer pudor ou sigilo em torno daquela ou de qualquer

7 De forma bastante resumida, o "cria" é a pessoa "nascida e criada" na favela, posição relativa a origem e ao local atual de residência de alguém. Para uma discussão do cria enquanto um elemento central na construção de relações de confiança para a regulação econômica e política das relações sociais na favela, ver ALBERNAZ (2018).

8 Drone ajuda polícia a localizar chefe do tráfico de drogas no morro do Palácio, em Niterói. Disponível em: https://noticias.r7.com/rio-de-janeiro/cidade-alerta-rj/videos/drone-ajuda-policia-a-localizar-chefe-do-trafico-de-drogas-no-morro-do-palacio-em-niteroi-21022018. Acesso em: 12 maio 2020.

9 Na PMERJ, o GAT é considerada uma modalidade de policiamento de guarnição, em que um grupo de quatro a oito policiais, divididos em duas ou mais viaturas, é responsável por intervenções que necessitem o emprego tático de força com vistas a assumir o controle de uma situação crítica. Na prática, o GAT é considerado um policiamento de "pista" voltado para "fazer guerra" (ALBERNAZ, 2010; RAMOS, 2018) e que demanda um determinado tipo de perfil de policial. Segundo Rodrigo Nogueira, ex-policial militar e autor de "Como Nascem os Monstros", em entrevista ao site APublica.org: “(...) você vai formando e selecionando por esse critério. Se você é duro, você vai trabalhar na patrulha, no GAT (Grupamento de Ações Táticas), na Patamo (Patrulhamento Tático Móvel)... Agora você que é mais sensato, que não vai se permitir determinadas coisas, não tem condições de você trabalhar nos serviços mais importantes. Não tem como o camarada sentar no GAT se não estiver disposto a matar ninguém. Não tem como. E não é matar só o cara que tá com a arma na mão ali, é matar porque a guarnição chega a essa conclusão: 'Não, aquele cara ali a gente tem que matar.' Aí é cerol mesmo. Se você não estiver disposto a participar disso aí, tu não vai sentar no GAT, não vai sentar numa patrulha nunca (...)”. Disponível em: https://bit. ly/3go1G1n. Acesso em: 12 mai. 2020. Segundo um sargento PM da ativa, em entrevista ao pesquisador Leonardo Ramos (2017), "o critério para este tipo de trabalho [de GAT] é que alguém sabe que você vai fazer a maldade que tem que se fazer." (p.32). 
outra morte de pessoas ditas envolvidas no Palácio naquela época. Encontravam-se menções bastante gráficas a elas em perfis pessoais de redes sociais, grupos de mensagens, em páginas de $b \log s$, elas circulam amplamente na rede. A única coisa que sabíamos era que a polícia tinha sido a principal responsável. Assumidamente responsável; sua autoria não estava mais na ordem do rumor. Eu sabia disso, porque os policiais contavam isso como "produtividade policial". Eles lançavam as fotos na internet, forneciam os relatos das ocorrências das mortes para serem anunciadas em sites de notícias locais, mencionavam-nas e eram felicitados por elas nas reuniões do Conselho Comunitário de Segurança (CCS) da região.

Essa contagem mortal impregnava as paredes do Morro do Palácio com várias mensagens de lamento. "Saudades de fulano", "saudades de sicrano", memórias de pessoas que, naqueles dois anos de convivência na favela, não tive a oportunidade de conhecer, estavam mortas quando cheguei lá. O rapaz cujo corpo jazia na escadaria seria mais um dos nomes estampados, marco dessa triste memória que habita os muros da favela. Entre os rostos da multidão que ocupava a Barreira naquela noite, reconheci a esposa e um dos filhos do rapaz morto, uma criança de, no máximo, dois anos. Wellerson estava comigo, ele disse:

"Esses moleques que você tá vendo morrer, tudo jogou comigo no meu time
[de futebol], tinha uns 23 anos, deixou filho de um ano, o garoto nem sabe o
que aconteceu com o pai; vai ter 12 anos e vai perguntar o que aconteceu que
todo mundo fala. Imagina a cabeça desse moleque? As pessoas chegarem pra
você e mostrarem o beco em que seu pai morreu."

Naquela mesma semana, fui à reunião do CCS do $12^{\circ} \mathrm{BPM}$. Queria observar como aquelas mortes seriam tratadas na reunião mensal do Conselho Comunitário de Segurança, órgão participativo que busca promover a "democratização" da política pública de segurança no estado do Rio de Janeiro, que conta com a presença de moradores e de autoridades públicas locais, incluindo representantes das polícias estaduais. Eu observei estas reuniões por mais de um ano durante a minha pesquisa.

\section{PELOS GUERREIROS QUE TOMBARAM EM COMBATE}

Àquela altura, as diferentes performances da polícia militar no Palácio já me intrigavam. Aquela polícia não era a polícia do container; pelo menos não condizia com o que eu tinha observado até aquele ponto. Sentada na barraca do Alberto no Chapadão, bem ao lado do 
container, um ponto isolado no alto da favela onde fica também o campo de futebol, tinha me acostumado a ver os policiais de bermuda e chinelo, assistindo aos jogos, bastante relaxados. A polícia do container não circulava pelos becos, apenas pela rua principal da favela. Em dias comuns, a viatura subia sem assombro, acionando um alerta sonoro característico quando se aproximava da região da boca de fumo, parecendo querer anunciar a sua passagem. Essa harmonia de forças, sustentada pelos pactos da sociabilidade violenta, não era vista como negativa pelos moradores, como mencionei anteriormente, um vez que tinha significado a redução das tentativas de invasão da antiga facção do Palácio. A disrupção do cotidiano agora vinha dos GATs de fora, que entravam no Palácio em busca da produtividade, conhecida no jargão policial militar como a "meritória"10.

Fui à reunião mensal do Conselho Comunitário de Segurança (CCS) na semana seguinte em que ocorreu a morte na Barreira. Esperava ouvir alguma coisa sobre as mortes ocorridas no Palácio naquele mês. No dia marcado para a reunião, com a mesa posta, o presidente do CCS começou anunciando o Hino Nacional. Todos ficaram de pé; era assim em todas as reuniões. Em seguida, o presidente pediu um minuto de silêncio "pelos guerreiros que tombaram em combate", se referindo aos policiais que foram mortos ou feridos naquele mês em "consequência da guerra social, da guerra urbana, do combate de guerrilha que infelizmente vivemos", explicou ele. A pauta da reunião era o "aumento do roubo de cargas e a apresentação das estatísticas criminais", segundo a convocatória. Várias ocorrências envolvendo "autos de resistência" 11 e "trocas de tiro" foram mencionadas, todas aclamadas pelos presentes como resultados positivos do trabalho policial.

Nas outras vezes em que tinha estado nessa reunião, o trabalho do então comandante da companhia responsável pelo Palácio tinha sido bem elogiado. Os indicadores acompanhados nas reuniões, à época, eram os mesmos listados pelo Sistema Integrado de Metas (SIM), projeto da Secretaria de Estado de Segurança (SESEG) que, até o ano de 2016, pagava prêmios em dinheiro aos policiais de batalhões responsáveis por reduções nos índices de ocorrência de crimes

10 Muito embora não necessariamente se refira a qualquer critério objetivo de aferição de performances, a expressão deriva da palavra "mérito" e é utilizada no jargão policial para se referir a todos os benefícios formais e informais auferidos pelo/a policial em decorrência de seu desempenho afinado às prioridades estabelecidas por comandantes e superiores hierárquicos, como folgas e prêmios em dinheiro.

11 Nas reuniões, tanto os policiais presentes, quanto a audiência civil e a presidência da mesa do CCS se referiam a expressão "auto de resistência", uma nomenclatura que foi abandonada recentemente, em 2016, em razão da edição de uma resolução conjunta do Conselho Superior de Polícia, órgão da Polícia Federal do Brasil, e do Conselho Nacional dos Chefes da Polícia Civil. Em seu lugar, passou a adotar-se, no Registro de Ocorrência (RO), a terminologia "homicídio decorrente de intervenção policial". Apesar da recorrência nas falas, nos gráficos apresentados nas reuniões do CCS a nomenclatura utilizada é a prevista naquela Resolução. 
considerados prioritários $^{12}$. O SIM também acompanhava a letalidade policial, premiando os registros de redução dos homicídios decorrentes de intervenção da polícia; entretanto, pelos menos nas reuniões do CCS de Niterói, o aumento da letalidade, principalmente nas favelas, não causava assombro algum. Os comandantes de companhia mencionavam abertamente os autos de resistência ocorridos naquele mês como se parte fossem de sua produtividade. "Essa semana tivemos uma ocorrência de vulto no Preventório; uma guarnição do GAT atingiu um marginal que tentava se evadir passando de moto de uma comunidade para a outra", disse um deles na ocasião. Relatos assim eram comuns. Todos destacavam ocorrências envolvendo mortes ocorridas em áreas de favelas de Niterói como "ocorrências de vulto".

Igualmente comuns eram as felicitações que se seguiam a esse tipo de intervenção. "Gostaria de parabenizar o comandante [nome] pelo ótimo trabalho que ele tem desempenhado a frente da região; parabéns, comandante, pela ocorrência no Preventório", disse um morador de São Francisco, bairro vizinho ao Morro do Preventório. Nenhum representante do Preventório fez qualquer comentário sobre o ocorrido. Lembro-me de ter visto duas pessoas da Associação do Cavalão; eu as conhecia, por isso as identifiquei, não porquê tenham se pronunciado na reunião. Ninguém do Palácio estava lá, disso eu tinha absoluta certeza. À despeito da ausência de suas lideranças, a favela era presença constante nas reuniões; não como voz autônoma e creditável, mas como autoria usurpada, imagem imposta de fora. Sua presença nas reuniões servia para lembrar aos presentes da situação excepcional em que operariam as forças policiais, justificando sua forma de atuar na favela por meio da ideia de "ausência", como se o "problema da favela" fosse a falta de Estado não seus excessos.

\section{A PATAMO DO CAPITÃO E OS PORÕES DA PRODUTIVIDADE ${ }^{13}$}

12 Segundo a Secretaria de Estado de Segurança do Rio (SESEG), o Sistema de Metas e Acompanhamento de Resultados (SIM) é um modelo de gestão por desempenho, que tem por objetivo desencadear ações integradas de prevenção e controle qualificado do crime, nas suas respectivas regiões, por meio do estabelecimento de metas para a redução da incidência de "indicadores estratégicos de criminalidade". Os indicadores acompanhados à época eram letalidade violenta (homicídio doloso, lesão corporal seguida de morte, homicídio decorrente de intervenção policial e latrocínio); roubo de veículo e roubo de rua (roubo a transeunte, roubo em coletivo e roubo de celular).

13 Devido a posicionamentos assumidos em campo, a perspectiva da polícia sobre os eventos observados no Palácio acabou ficando muito restrita às observações in loco na favela e nas reuniões do CCS, e a conversas com colegas policiais, congregados em torno de grupos de pesquisa como o LAESP/UFF, Laboratório de Estudos sobre Conflitos, Cidadania e Segurança Pública, coordenado por mim e pelo Professor Lenin dos Santos Pires, da Universidade Federal Fluminense. Incorporo a perspectiva da polícia e da política pública de segurança também a partir da minha significativa experiência na administração pública da segurança (2009-2014), bem como a partir de estudos anteriores, realizados com foco no público policial. Ver: (ALBERNAZ et al., 2007; ALBERNAZ, 2009; 2010; ALBERNAZ \& MUNIZ, 2015; ALBERNAZ, 2015a; 2015b). 
A conflitualidade no Palácio só ganhava em proporções e a violência dos embates continuava a produzir suas vítimas. "Morreu um moleque", avisa Wellerson no grupo de mensagens dos amigos do Palácio; “Outro?”, respondi, "sim; e parece que mataram um policial”, complementou ele em seguida. Outro membro do grupo envia uma foto do rapaz; ele aparentava ter, se tanto, 18 anos. "Tá cheio de polícia no morro", avisou Wellerson, mandando a foto de uma rua de acesso ao Palácio (Nair Margem Pereira) com cerca de cinco viaturas de GAT estacionadas. “Balearam dois policiais!". Logo em seguida, ele esclarece que nenhum deles tinha morrido, na verdade. Começam a chegar recortes de informes nas redes sociais sobre o "tiroteio no Palácio". Chega então uma foto do rapaz morto no chão; ele era o quarto caso de homicídio decorrente de ação policial desde o início daquele turbulento ano de 2017.

Um dos rapazes comenta no grupo que "a polícia daqui [polícia do container] não sabia da operação", afirmando em seguida que os policiais da "Destacada do Palácio" estavam reclamando que eram sempre "rendidos" pelas operações dos GATs de fora da favela. "Eu converso muito com polícia, então eles me explicam, os caras são da $\mathrm{PATAMO}^{14}$ do capitão, o capitão chega pra eles e diz 'meu irmão, você tem que me trazer 5 mil, dá teu jeito', e os caras tem que correr atrás, senão eles perdem o privilégio, entendeu?”, complementou. Ele menciona ainda uma prática que seria atribuída aos GATs.

"O negócio do Sílvio, aquilo foram os caras da PATAMO, eles mandaram um maluco armado que não era polícia pra dar o bote na boca e o cara acabou matando um morador, mas os caras já estavam na favela; a gente tava achando que era invasão, mas eram os caras da PATAMO; quando mataram o 'frente' aqui também, foi a mesma coisa, a gente achando que era invasão, mas era a polícia; e os polícia do container não sabem de nada, eles ficam rendidos"15.

Ser alocado em um GAT - assim como em outras modalidades de policiamento "produtivas" e, consequentemente, rentáveis - é uma posição bastante cobiçada nos batalhões de polícia militar do Rio de Janeiro. Existe todo um mercado em torno dessas designações; mercados de lealdades, reputações e de dinheiro, inclusive. Os policiais chegam a pagar para serem alocados nesses serviços. O também chamado "GAT do comandante" (ou "PATAMO do Comandante"), seja do batalhão, seja das companhias, é uma posição de grande prestígio nas unidades. "É o GAT que o comandante manda para resolver o que tiver que ser resolvido", explicou-me um

14 Policiamento Tático Móvel, modalidade de policiamento assemelhada ao GAT.

15 Relato colhido em entrevista com um morador do Palácio. Estas (e outras) estratégias de produtividade são relatadas também pelo ex-praça da Polícia Militar do Rio de Janeiro, Rodrigo Nogueira, em seu "livro de memórias" da época em que ainda era um membro ativo da corporação, "Como Nascem os Monstros", editado em 2013, pela Topbook. 
Coronel PM numa reunião do CCS em Duque de Caxias ${ }^{16}$. Além das escalas diferenciadas e as chamadas "folgas meritórias", esse grupo afinado de pessoas é informalmente autorizado (e até estimulado) a recolher "espólios de guerra" ${ }^{17}$. A essa altura já se pode imaginar o quão cobiçada é essa posição pelos demais policiais, o que faz do "fogo amigo" ou "judaria interna", como dizem, dimensões muito comuns da vida dos agentes nos porões da produtividade policial ${ }^{18}$.

Ao trazer essas histórias para presente o artigo, gostaria de chamar a atenção para a questão da centralidade da chamada "produtividade policial" como meta organizacional, objeto do esforço e da ação dos membros da corporação policial, e como horizonte motivacional dos policiais implicados em atividades consideradas finalísticas para a sua situação de traba$1 h 0^{19}$. No caso da atuação da polícia militar no Palácio, era patente o modo como os ganhos de produtividade estavam diretamente associados ao exercício de um mandato oficioso sobre a vida e a morte. O exercício desse poder funcionava como uma poderosa força de mercado, de precificação de "mercadorias políticas" (MISSE, 2010) 20, como o arrego, e para a coleta de es-

$16 \mathrm{Na}$ época, eu fazia uma pesquisa sobre a "economia dos homicídios" na região da Baixada Fluminense, nos municípios de Duque de Caxias e São João de Meriti, e tive que assistir as reuniões mensais dos Conselhos Comunitários de Segurança (CCS) de ambos os municípios (ÁGUIDA; ALBERNAZ; GUILHERME; MARINHO, 2018).

17 A expressão "espólio de guerra" é elemento central do imaginário belicista e hipermasculinizado das organizações policiais fluminenses e constituem espécies de troféus e/ou prêmios tomados ilegalmente aos exércitos vencidos em situações de guerra. No caso das polícias, isso pode significar, por exemplo, a distribuição de dinheiro e outros objetos apreendidos entre os policiais diretamente envolvidos nas ocorrências, mas também rendimentos advindos da extorsão da própria população das favelas, consideradas territórios inimigos. Ao fim e ao cabo, o espólio pode ser tudo aquilo que o/a policial entenda possuir direitos em função de sua bravura e da "vitória sobre a morte" (cujo símbolo é a faca na caveira) em uma situação de conflito armado.

18 Segundo Leonardo Ramos (2017), "essa representação, que a figura de Judas empresta à categoria "judaria", sugere que aquele que pratica a "judaria" trai um grupo de iguais, grupo que compartilha os mesmos valores e intimidades. Em se falando do contexto policial, seria alguém que, em tese, deveria comungar da mesma "ética policial": um conjunto especial de regras e práticas que serve como fundamento para o exercício de uma interpretação autônoma da lei." (LIMA, 1995, p. 35).

19 Segundo Howard Becker (2008), a polícia não nutre um interesse especial em reforçar o conteúdo das regras propriamente ditas; seu interesse é modulado por uma avaliação privada da importância dos vários tipos de regras e infrações, que diferem, muitas vezes, do que é entendido como relevante para o público em geral. Para essa avaliação, as prioridades institucionais, metas e valores corporativos seriam mais relevantes que a própria lei para explicar a decisão policial de reforçar ou não uma regra. Nas palavras do autor, "[o]s impositores [de regras], portanto, respondendo às pressões de sua própria situação de trabalho, aplicam as regras e criam outsiders de forma seletiva. Se uma pessoa que comete um ato desviante será de fato rotulada de desviante depende de muitas coisas alheias ao seu comportamento efetivo: depende do agente da lei sentir que dessa vez deve dar alguma demonstração de que está fazendo o seu trabalho a fim de justificar a sua posição; de o infrator mostrar a devida deferência ao impositor; de o 'intermediário entrar em ação ou não; e de o tipo de ato cometido estar incluído na lista de prioridades do impositor.” (BECKER, 2008, p.165-166).

20 Segundo Misse (2010), o conceito de "mercadoria política" foi proposto com o objetivo de "operar analiticamente essa variedade de trocas e negociações ilícitas que correspondem, em grande parte, às representações sociais de 'corrupção', 'clientelismo', 'extorsão', 'tráfico de influência', 'fraudes econômicas' etc. Em todos esses casos, tenho insistido sobre a necessidade analítica de se abstrair a dimensão moral para compreender esses processos 
pólios e outras recompensas. No terreno, esses rendimentos estão ancorados em uma mecânica invisível de poder, amuralhada no cotidiano da favela, produzindo segregação como resultado do funcionamento de poderosas e obscuras forças de mercado. Nesses mercados, a legalidade e a ilegalidade funcionam de forma associada, produzindo e consumindo valores de maneira interdependente.

Obviamente, o ambiente de excepcionalidade criado por essa dinâmica tinha consequências dramáticas para os moradores do Palácio e de tantas outras favelas. A mais dramática delas, certamente, é sua alta exposição à violência letal; especialmente a juventude. Os moradores da favela podem ser mortalmente vitimados por esses conflitos mercadológicos violentos, seja pelas mãos dos grupos faccionais, seja da própria polícia. Neste último caso, as forças policiais têm atuado nas favelas e áreas periféricas da cidade munidas de uma espécie de licença para matar informal - embora amplamente aceita -, encontrando a legitimidade para suas ações sob o manto de um ideal de cidadania que esconde muito mais razões mundanas e particularistas para se agir em nome da sociedade.

\section{A POLÍTICA DO COTIDIANO E A REPRODUÇÃO SOCIAL DAS DESIGUALDADES}

No meu trabalho, a construção do Morro do Palácio como um "lugar" (BOURDIEU, 1984, 1997, 2013) na paisagem niteroiense se deu de frente para o mar, em meio a aquinhoados e intelectuais, do convívio com heranças oligárquicas conservadoras e da atmosfera provinciana da cidade. "Foi essa cidade que fez essa favela", disse-me uma liderança comunitária do Palácio. Além de olhar para a favela enquanto uma posição relativa na estrutura de distribuição de pessoas e propriedades na cidade de Niterói, minha pesquisa adotou a perspectiva de lançar sobre o cotidiano palaciano um olhar atento a sua dimensão política. Por conta dessa escolha,

sociais como mais uma forma, não exclusivamente econômica, de mercado ilegal. A minha insistência, nesse caso, decorre da constatação de que se trata, quase sempre, de transações que lesionam mais a moral pública que a privada, que atingem mais o Estado do que o indivíduo, e que aspiram a alguma legitimidade particularista ou, ao menos em certos casos, encontram alguma justificação moral ou neutralização da culpa. Ao atingirem o Estado, alcançam seja a sua soberania, seja o seu monopólio de regular o mercado econômico, administrar a justiça e criminalizar conflitos e cursos de ação com base no emprego legítimo da violência. Mas essa ofensa não ganha, no plano moral, a mesma dimensão que a lei lhe outorga. A distinção entre moral pública e moral privada não é sempre clara para os atores e oscila de acordo com os interesses em jogo, com base, num extremo, no ethos democrático moderno e, no outro extremo, simplesmente no ethos individualista egoísta.” (MISSE, 2010, p. 99). 
ganhou destaque em meus argumentos o caráter perversamente banal da operação dos dispositivos de reprodução das desigualdades, em sua articulação com as táticas de sobrevivência da população favelada. Vistas também como formas de resistência criativa (DE CERTEAU, 1997) ${ }^{21}$, argumento que, em ambientes periféricos, em que as pessoas gozam de um status de cidadania igualmente precarizado ${ }^{22}$, as táticas de viabilização do cotidiano podem investir-se de uma dimensão conservadora que não deve ser desconsiderada.

No caso do Palácio, aqui olhado a partir da relação da favela com a sua situação de vizinhança radical, observei pessoas buscando emprego, se divertindo, os movimentos do comutar diário e as transformações na dinâmica de relações da sociabilidade violenta. Por meio da intensidade de histórias de vida, minha imaginação sociológica perseguiu ainda a ideia de que o Palácio, enquanto espaço segregado, era um lugar em que precariedades eram transacionadas como mercadorias. Busquei refletir sobre as trocas e os rendimentos advindos desses trânsitos como uma espécie de operação de câmbio, em que a diferença entre o valor das "moedas" em diferentes mercados e circuitos de circulação produziria (quando a operação era bem executada) em rendimentos políticos, econômicos e reputacionais para aqueles que operavam em seu limiar. No trânsito entre os mundos da "cidadania formal" e da "cidadania precária", a ação da polícia - em especial, da Polícia Militar - desempenhava um papel crucial.

A fala de uma moradora antiga do Morro do Palácio é extremamente elucidativa nesse sentido.

A polícia que entra trocando tiro é outra polícia; os policiais daqui tomam o refrigerante deles, a água deles e quando dá $17 \mathrm{~h}$ metem o pé. Os que rodam a favela, vem só fazer furdunço. (...) Mas o que rola mesmo é até perigoso botar isso aí na sua pesquisa. Você tem 'renda' [arrego]? Se não, tem vamos trabalhar. Se não tem faz-me rir, começa a morrer gente".

Ela me disse, explicando a relação entre a violência policial e o arrego na favela, uma

\footnotetext{
21 Utilizo aqui a discussão de Michel De Certeau (1997), com a diferenciação entre "tática" e "estratégia". Apenas aquele que possui total domínio sobre seus recursos pode ter uma estratégia. Para os pobres e periféricos, portanto, as táticas operativas do cotidiano, segundo o autor, seriam "maneiras de fazer" que usam a economia cultural dominante segundo seus interesses próprios e suas próprias regras. Constituem práticas criativas por meio das quais os "usuários", consumidores de cultura, se reapropriam do espaço organizado pelas técnicas da produção sociocultural.

22 Percorrendo as análises, pode-se perceber que utilizamos o termo "precariedade", na presente etnografia, como sugerido por Pires (2017), como um termo polissêmico, que incorpora não só a situação de precariedade jurídica gerada pela "situação de posse", mas de um regime ou conjunto progressivo de precariedades associadas - despadronizações, inconstâncias e desacreditações - que, em última análise, produz efeitos sobre o status de cidadania dos sujeitos.
} 
relação direta de precificação e extração de valor. A polícia do container é a polícia dos pactos locais. Por estar precariamente instalada no topo do Palácio, vê-se impedida de "produzir". O GAT, uma polícia que vem de fora, já não tem sua produtividade constrangida pelos mesmos pactos e usa a violência aberta para extrair rendimentos políticos, materiais e reputacionais do lusco fusco legal da favela. Os efeitos políticos dessa forma de atuação sobre o mundo da cidadania real ${ }^{23}$ parece implicar a instauração de um estado de excepcionalidade constante, em que um Estado descredibilizado pode dar provas de sua força e materialidade.

Os impactos de precarização da violência armada sobre a favela incidem sobre o status de cidadania de seus moradores e sobre as condições materiais do espaço, como mencionado anteriormente. Mas nada me deixava mais impressionada do que as alianças perversas que essa violência construía no cotidiano palaciano. Do meu tempo no Palácio, a reação dos moradores e moradoras adultos da favela a erupção de mais aquele ciclo de violência era de uma naturalização impressionante ${ }^{24}$. Parecia-me que algumas pessoas chegavam no limiar da culpabilização daqueles que tinham sido mortos. "Fulano deu mole", ouvi diversas vezes ${ }^{25}$. Dona Denise, cujo filho tinha sido expulso da favela pelo movimento, celebrava a morte dos bandidos em tom de confidência; "graças a Deus, minha filha, e quem entra pra essa vida sabe que é do jogo", disse-me. A morte de Sílvio, primeiro jovem a ser fatalmente vitimado durante o ciclo de violência de 2017, sentado em frente ao bar de seu sogro, suscitou os seguintes comentários: "não, ele não era da boca; já foi né, tomou tiro, mas hoje ele só ficava moscando o movimento, tirando onda com a cara dos outros". Por conta dessa proximidade e seus rendimentos reputacionais na favela, disseram-me, Sílvio teria sido compelido moralmente a intervir no episódio do "bote na boca do Palácio", o que teria dado consecução a sua morte ${ }^{26}$.

Em todos os ciclos de violência vividos no Palácio nos últimos dez anos antes do início da minha pesquisa, a violência policial tinha tido um papel a desempenhar, seja para a desestabilização de processos sucessórios internos do movimento, seja para as dinâmicas de alternância no domínio faccional sobre a boca da favela. Nas reuniões do Conselho Comunitário

23 A discussão teórica desenvolvida nesta seção toma emprestada a distinção entre os regimes de "cidadania formal" e a "política dos governados" ou "cidadania real" de Partha Chatterjee, que nos fala sobre as formas de apropriação, nos rincões "tradicionais" indianos, de "valores democráticos" trazidos pelo contato com a burocracia do Estado (CHATTERJEE, 2004).

$24 \mathrm{Com}$ as crianças era diferente. Elas me pareciam profundamente impactadas pelo medo, recusando-se a sair de casa, sobressaltando-se com o barulho de fogos, muitas apresentavam sinais de um trauma profundo.

25 Para a análise da categoria "deu mole" enquanto explicação nativa do infortúnio de moradores baleados e/ou mortos em confrontos armados entre policiais e traficantes em uma favela de Senador Camará, ver Borges (2019).

26 Ver relato em destaque nas páginas 11-12 no presente artigo. 
de Segurança local (CCS12), estas mortes viravam reputação, capital político e bonificações. Na política eleitoral de Niterói, a violência podia se constituir em risco político, mas jogava uma mão obscura na criação e manutenção de "currais eleitorais" da pobreza na cidade. Minha experiência de campo no Palácio fez emergir o papel da violência sobre processos localizados de formação de Estado na relação entre a favela, uma ficção capturada de sociedade civil27, mormente legitimadora da violência e dos objetivos das burocracias estatais, e o que chamei na tese de "forças do interesse público"28.

No Palácio, a captura de um certo idioma de cidadania por uma poderosa ideia de Estado (ABRAMS, 1988) e seus meios de violência servia a lógica de reprodução do que chamei de "grupos dirigentes locais" 29 . Essa miríade de interesses explorava a ilegalidade de áreas periféricas como o Palácio, instrumentalizando seus rendimentos em escalas de eventos conexos (REVEL, 1998) ${ }^{30}$, em que o Estado, enquanto força do interesse público, era produzido na favela e produzia a favela num ciclo vicioso de mútua dependência. Pode-se dizer que esse processo cíclico faz avançar visões autoritárias que, em face do espetáculo da violência, exploram a predisposição de alguns de abrir mão de garantias e direitos (não dos próprios, obviamente), autorizando o avanço do campo estatal sobre as liberdades individuais em nome do medo; medo este reiterado e fortalecido pelas mesmas medidas tomadas em seu nome.

27 Lançando mão da discussão de Partha Chatterjee (2014), proponho que o "Estado", ao recorrer à sociedade civil em busca da legitimação de suas ações na chave do interesse público, trata, em verdade, com grupos de elite modernos, isolados da vida popular mais ampla das comunidades, cercados de enclaves de liberdade cívica e lei racional (CHATTERJEE, 2014, p. 4).

28 Conjugado a lógica de reprodução dos grupos dirigentes, das oligarquias políticas e econômicas locais, aquilo que chamei na tese de "forças de interesse público" se refere a um conluio de atores institucionais simbólica e politicamente consagrados pelo poder ilocucionário do campo estatal de dizer o "interesse público". Ao promover um projeto de cidade, em nome da qual exerceriam o seu poder, submetendo qualquer oposição em contrário, constituem formas ditas neoliberais de espacialização operando em uma área "conurbada" entre os interesses do Estado e do capital no que se refere ao desenvolvimento econômico e a regulação do mercado de trabalho da cidade de Niterói (ALBERNAZ, 2018).

29 A categoria é aqui tomada a uma discussão sobre as lógicas de sucessão de "grupos dirigentes" no Brasil, sendo tributária, em especial, da noção de "contra-elite" de José Murilo de Carvalho, autor que expõe magistralmente as facetas do conservadorismo no Brasil referindo-se a ação de grupos políticos que manobram para suceder o "grupo dirigente" no monopólio dos mecanismos de poder, com foco na manutenção do status quo (CARVALHO, 1996). Para um maior detalhamento da atuação política dos grupos dirigentes fluminenses e suas posições sobre temas como o fim da escravidão ou a proclamação da república, por exemplo, ver também Lemos e Do Couto (2012) e Fernandes (2016).

30 "O problema aqui não é tanto opor um alto e um baixo, os grandes e os pequenos, e sim reconhecer que uma realidade social não é a mesma dependendo do nível de análise - ou, como muitas vezes se dirá nesse livro, de escala de observação - em que escolhemos nos situar. Fenômenos maciços, que estamos acostumados a pensar em termos globais, como o crescimento do Estado, a formação da sociedade industrial, podem ser lidos em termos completamente diferentes se tentamos apreendê-los por intermédio das estratégias individuais, das trajetórias biográficas, individuais ou familiares, dos homens que foram postos diante deles.” (REVEL; ABÉLÈ; LEPETIT, 1998, p. 13) 


\section{CONSIDERAÇÕES FINAIS: MERCADOS DA DESIGUALDADE E 0 GOVERNO DA (IN)SEGURANÇA}

Qual é a política da segurança, para além da política de segurança pública? A polícia justifica sua existência profissional pela atribuição de fiscalizar e garantir a adesão dos indivíduos a um determinado regramento, seja ele legal ou consuetudinário. O imaginário que cultiva como linha de frente no combate ao crime, sua estrutura organizacional, seu treinamento, mecanismos de controle e parâmetros de avaliação e produtividade tendem a caracterizar a polícia como uma "burocracia de cumprimento da lei”. A lei, entretanto, não é capaz de antever todas as condutas concretas dos sujeitos, e a polícia, por sua vez, também não é sua mera replicadora. Seu espectro de intervenção (o que a polícia de fato faz) supera de longe o argumento que justifica a legalidade de suas ações e seus objetivos manifestos (BITTNER, 2003; LIMA, 1995, 2013; MUNIZ, 1999, 2006).

No caso do Morro do Palácio, uma favela de Niterói ${ }^{31}$, busquei apresentar os efeitos de repercussão da atuação policial para além de suas consequências imediatas sobre o cotidiano dos moradores e moradoras, explorando sua dimensão política e seus potenciais rendimentos econômicos, entre o legal e ilegal. Nesse sentido, busquei destacar o papel da segurança no funcionamento de dispositivos de reprodução da estrutura das desigualdades e seus rituais de desigualação em sua operação insidiosa sob o manto da democracia participativa brasileira (DAMATTA, 1979; CARVALHO, 2001; AMORIM; LIMA; MENDES, 2005).

Essas forças de conservação na mudança, trabalhando fortemente ancoradas no cotidiano do Palácio, participavam da (re)produção do status quo da desigualdade social e da exclusão na cidade de Niterói. Em última análise, como mais tarde se tornou claro, a interação dessas forças resultava em uma elaborada técnica de governo (FOUCAULT, 2008a, 2008b), uma economia que tinha seu lado visível, beneficiando oligarquias políticas e econômicas, mas também jogava uma mão oculta nas sombras da ilegalidade, criando um ambiente lucrativo para todos os tipos de oportunistas da insegurança. Operando por meio de mecânicas de poder localizadas, esse dispositivo se beneficiava, como me referi, de uma espécie de idioma capturado de cidadania, na relação com uma sociedade civil mormente legitimadora da ação da polícia, que participava da construção de uma referência de interesse público que negava a participação dos

31 Para um relato sobre a formação das favelas de Niterói, ver Albernaz (2020). Disponível em: https://wikifavelas.com.br/index.php?title=Favelas_de_Niter\%C3\%B3i. Acesso em: 12 maio 2020. 
moradores e moradoras do Palácio no mesmo universo de direitos que protegia as pessoas de fora da favela.

\section{REFERÊNCIAS}

1. ABRAMS, P. Notes on the difficulty of studying the state. Journal of Historical Sociology, n. 1, v. 1, p. 58-89, 1988. Disponível em: https://onlinelibrary.wiley.com/doi/ abs/10.1111/j.1467-6443.1988.tb00004.x. Acesso em: 01 fev. 2020.

2. ÁGUIDA, Juliana; ALBERNAZ, Elizabete; GUILHERME, Raquel; MARINHO, Leandro. Homicídios na Baixada Fluminense: Estado, Mercado, Criminalidade e Poder. Comunicações do ISER, n. 71, ano 37, 2018. Disponível em: https://www.iser.org.br/ publicacao/comunicacoes/71/. Acesso em: 15 maio 2020.

3. ALBERNAZ, Elizabete R.; CARUSO, Haydée; PATRÍCIO, Luciane. Tensões e desafios de um policiamento comunitário em favelas do Rio de Janeiro. São Paulo em Perspectiva, v. 21, n. 2, p. 39-52, 2007. Disponível em: http://produtos.seade.gov.br/ produtos/spp/v21n02/v21n02_04.pdf. Acesso em: 20 mar. 2020.

4. ALBERNAZ, Elizabete. "Deus e o Diabo na terra do sol”: visões de espaço público, ética profissional e moral religiosa entre policiais militares evangélicos do Rio de Janeiro. 2009. Dissertação (Mestrado em Antropologia) - Programa de Pós-Graduação em Antropologia Social, Museu Nacional, Universidade Federal do Rio de Janeiro.

5. ALBERNAZ, Elizabete. Na fronteira entre o bem e o mal: ética profissional e moral religiosa entre policiais militares evangélicos cariocas. Caderno CRH, v. 23, n. 60, p. 525-539, 2010. Disponível em: https://www.scielo.br/pdf/ccrh/v23n60/v23n60a06.pdf. Acesso em: 10 mar. 2020.

6. ALBERNAZ, Elizabete; MUNIZ, Jacqueline. Moralidades entrecruzadas nas UPPs: Uma narrativa policial. Cadernos Ciências Sociais, v. 2, p. 115-151, 2015. Disponível em: https://app.uff.br/riuff/handle/1/11976. Acesso em: 05 abr. 2020.

7. ALBERNAZ, Elizabete Ribeiro. Sobre legitimidade, produtividade e imprevisibilidade: seletividade policial e a reprodução da ordem social no plano de uma certa "política do cotidiano". Confluências, Revista Interdisciplinar de Sociologia e Direito, v. 17, n. 2, p. 86-99, 2015. Disponível em: https://periodicos.uff.br/confluencias/article/ viewFile/34493/19896. Acesso em: 20 abr. 2020.

8. ALBERNAZ, Elizabete. "Faro Policial": um estudo de caso acerca dos critérios de construção e operação de padrões de suspeição e seletividade na ação policial. In: ENCONTRO ANUAL DA ASSOCIAÇÃO NACIONAL DE PÓS-GRADUAÇÃO E PESQUISA EM CIÊNCIAS SOCIAIS, 39., 2015, Caxambu. Anais..., Caxambu: 
ANPOCS, 2015.

9. ALBERNAZ, Elizabete. Palácios sem reis, democracias sem cidadãos: política, cotidiano e a formação de mercados da exclusão em dois contextos do "sul-global". 2018. Tese (Doutorado em Antropologia) - Programa de Pós-Graduação em Antropologia, Universidade Federal Fluminense, Niterói.

10. ALBERNAZ, Elizabete. "Favelas de Niterói". Verbete. In: Dicionário de Favelas Marielle Franco. Disponível em: https://wikifavelas.com.br/index.php?title=Favelas de _Niter\%C3\%B3i. Acesso em: 29 mar. 2020.

11. AMORIM, Maria Stella de; LIMA, Roberto Kant de; MENDES, Regina Lúcia Teixeira. Ensaios sobre a igualdade jurídica: acesso à justiça criminal e direitos de cidadania no Brasil. Rio de Janeiro: Editora Lumen Juris, 2005.

12. BITTNER, Egon. Florence Nightingale procurando Willie Sutton: uma teoria da polícia. Aspectos do trabalho policial. São Paulo: EdUSP, 2003.

13. BOURDIEU, Pierre. Distinction: A social critique of the judgement of taste. Cambridge: Harvard University Press, 1984.

14. BOURDIEU, Pierre. Efeitos de lugar. In: BOURDIEU, P. (Org.). A Miséria do Mundo. Petrópolis: Vozes, 1997.

15. BOURDIEU, Pierre. Espaço físico, espaço social e espaço físico apropriado. Estudos Avançados, v. 27, n. 79, p. 133-144, 2013. Disponível em: http://www.revistas.usp. br/ eav/article/view/68707. Acesso em: 29 mar. 2020.

16. BORGES, Gabriel. "Quantos ainda vão morrer, eu não sei”: o regime do arbítrio, da curtição, morte e a vida em um lugar chamado de favela. 2019. Tese (Doutorado em Sociologia e Direito) - Programa de Pós-Graduação em Sociologia e Direito, Univerisdade Federal Fluminense, Niterói.

17. CARVALHO, José Murilo de. A construção da ordem. A elite política imperial. Teatro de Sombras. A política imperial. (2a ed. rev.). Rio de Janeiro: Editora UFRJ/Relume Dumará, 1996.

18. CARVALHO, José Murilo de. Cidadania no Brasil. O longo caminho, Rio de Janeiro: Civilização Brasileira, 2001.

19. CHATTERJEE, Partha. The politics of the governed: reflections on popular politics in most of the world. Columbia University Press, 2004.

20. CECCHETTO, Fátima Regina; MUNIZ, Jacqueline de Oliveira; MONTEIRO, Rodrigo de Araujo. "BASTA TÁ DO LADO"- a construção social do envolvido com o crime. Caderno CRH, v. 31, n. 82, p. 99-116, 2018. Disponível em: https://www.scielo.br/ pdf/ ccrh/v31n82/0103-4979-ccrh-31-82-0099.pdf. Acesso em: 15 mar. 2020.

21. CHATTERJEE, Partha. The politics of the governed: reflections on popular politics in 
most of the world. Columbia University Press, 2004.

22. DAMATTA, Roberto. Carnavais, malandros e heróis: para uma sociologia do dilema brasileiro. Rio de Janeiro, Rocco, 1979

23. DAS, Veena et al. Anthropology in the Margins of the State. PoLAR: Political and Legal Anthropology Review, v. 30, n. 1, p. 140-144, 2004. Disponível em: https://pdfs. semantic scholar.org/f40e/4e99a2a660dc9958374056462d884f52aa3c.pdf. Acesso em: 05 maio 2020.

24. DE CERTEAU, Michel et al. A invenção do cotidiano: morar, cozinhar. Rio de Janeiro: Vozes, 1997.

25. FERNANDES, Maria Fernanda Lombardi. Alberto Torres e o conservadorismo fluminense. Especiaria: Cadernos de Ciências Humanas, v. 10, n. 17, p. 277-301, 2016. Disponível em: https://periodicos.uesc.br/index.php/especiaria/article/view/910. Acesso em: 08 maio. 2020.

26. FOUCAULT, Michel. Nascimento da biopolítica: curso dado no Collège de France (1978-1979). São Paulo: Martins Fontes, 2008.

27. FOUCAULT, Michel. Segurança, território, população. São Paulo: Martins Fontes, 2008.

28. LEMOS, E. NETO DO COUTO, Renato Luís. Como o Açúcar no Café: escravidão, ideologia e política no republicanismo fluminense. In: CÔRTE, Andréa Telo de. (Org.). História Fluminense: novos estudos. Niterói: Centro de Estudos de História Fluminense, 2012 .

29. LIMA, Roberto Kant de. A polícia da cidade do Rio de Janeiro: seus dilemas e paradoxos. Rio de Janeiro: Ed. Forense, 1995.

30. LIMA, Roberto Kant de. Entre as leis e as normas: Éticas corporativas e práticas profissionais na segurança pública e na Justiça Criminal. Dilemas, v. 6, n. 4, out./nov./ dez., 2013. Disponível em: https://app.uff.br/riuff/bitstream/1/5326/1 /artigo_kant_ revista_dilemas_0.pdf. Acesso em: 08 maio 2020.

31. MACHADO DA SILVA, Luiz Antonio. Sociabilidade violenta: por uma interpretação da criminalidade contemporânea no Brasil urbano. Sociedade e estado, v. 19, n. 1, p. 53-84, 2004. Disponível em: https://www.nescon.medicina.ufmg.br/biblioteca/imagem/1015. pdf. Acesso em: 15 mar. 2020.

32. MISSE, Michel. Trocas ilícitas e mercadorias políticas: para uma interpretação de trocas ilícitas e moralmente reprováveis cuja persistência e abrangência no Brasil nos causam incômodos também teóricos. Anuário Antropológico, n. 2, p. 89-107, 2010. Disponível em:https://periodicos.unb.br/index.php/anuarioantropologico/article/view/7029. Acesso em: 05 mar. 2020.

33. MUNIZ, Jacqueline. Ser policial é, sobretudo, uma razão de ser: cultura e cotidiano 
da Polícia Militar do Estado do Rio de Janeiro. 1999. Tese (Doutorado), Instituto Universitário de Pesquisas do Rio de Janeiro, Rio de Janeiro.

34. MUNIZ, Jacqueline. Discricionariedade policial e a aplicação seletiva da lei na democracia. Algumas lições extraídas de Carl B. Klockars". São Paulo: NEV-USP, 2006.

35. NOGUEIRA, Nogueira Batista. Como Nascem os Monstros: a história de um exsoldado da polícia militar do Estado do Rio de Janeiro. Rio de Janeiro: Topbooks, 2013.

36. PEIRANO, Mariza. A Teoria Vivida: E Outros Ensaios. Rio de Janeiro: Zahar, 2006.

37. PIRES, Lenin. Precários e perigosos: possíveis relações entre formalidade e informalidade em processos de administração de conflitos no Rio de Janeiro. In: GLEDHILL, J.; HITA, M. G.; PERELMAN, M. D. (Eds.) Disputas em Torno do Espaço Urbano: Processos de Produção /Construção e Apropriação da Cidade. Salvador: Editora UFBA, 2017, p. 335-352.

38. REVEL, Jacques. Jogos de escalas: a experiência da microanálise. Editora Fundação Getúlio Vargas, 1998.

39. RAMOS, Leonardo dos Santos. Entre a "judiaria interna", a "pista salgada" e o "medo de se entregar": uma etnografia das representações de medo entre policiais militares do Estado do Rio de Janeiro. 2017. Trabalho de Conclusão de Curso (Bacharelado em Segurança Pública) - Universidade Federal Fluminense, Niterói.

\section{Elizabete Ribeiro Albernaz}

Doutora em Antropologia pela Universidade Federal Fluminense, Pós-doutorado pelo Instituto de Estudos Comparados em Administração Institucional de Conflitos (INCT-InEAC) e Visiting Researcher na University of the Witwatersrand. ID ORCID: http://orcid.org/0000-0003-30831473. E-mail: betealbernaz@gmail.com. 